\title{
Diurnal Variation of Seasonal Precipitation over the CONUS: A Comparison of Gauge Observations with TRMM Data
}

\author{
Liming Zhu ${ }^{1},{ }^{1}$ Yu Zhao, ${ }^{2}$ Xiaoping Rui, ${ }^{3}$ and Qingwei Wei ${ }^{4}$ \\ ${ }^{1}$ College of Hydraulic Science and Engineering, Yangzhou University, Yangzhou 225009, China \\ ${ }^{2}$ College of Information Engineering, Yangzhou University, Yangzhou 225009, China \\ ${ }^{3}$ School of Earth Sciences and Engineering, Hohai University, Nanjing 211000, China \\ ${ }^{4}$ Hebi Meteorological Bureau, Hebi 458030, China \\ Correspondence should be addressed to Liming Zhu; zhuliming0101@126.com
}

Received 12 September 2020; Accepted 15 December 2020; Published 24 December 2020

Academic Editor: Panagiotis Nastos

Copyright (๑) 2020 Liming Zhu et al. This is an open access article distributed under the Creative Commons Attribution License, which permits unrestricted use, distribution, and reproduction in any medium, provided the original work is properly cited.

\begin{abstract}
Diurnal variation of precipitation is a fundamental periodic signal of local climate. Comprehensive study of diurnal variation of precipitation is helpful in studying the formation of local climate and validating satellite precipitation products. In this study, a comparison is drawn between precipitation gauge observations and Tropical Rainfall Measuring Mission (TRMM) 3B42 data on diurnal variation of precipitation. First, using the $K$-means clustering algorithm, stations with gauge observations and pixels with TRMM data are divided into different groups according to the diurnal variation of precipitation, respectively. In each group, the stations have similar diurnal variation of precipitation. Then maps of diurnal variation of precipitation for gauge observations and TRMM data are obtained. According to these maps, the diurnal variation of precipitation over the contiguous United States (CONUS) presents seasonal variability in both gauge observations and TRMM data. In addition, the diurnal variation of precipitation shows clustered features in space. However, the spatial patterns of the obtained maps do not match, and the TRMM satellite data perform poorly in capturing the hourly precipitation event. Finally, the possible mechanism behind the prevailing nocturnal precipitation over the middle of the CONUS is discussed, with the prevailing nocturnal precipitation judged likely to be strongly related to the mountain-plains solenoid (MPS) circulation.
\end{abstract}

\section{Introduction}

Diurnal variation of precipitation is a periodic signal at subdaily scale and can be used to characterize local climate [1-3]. Driven by solar radiation and affected by heterogeneous underlying surface, it shows remarkable seasonal variability and regional difference. A comprehensive study of diurnal variation of precipitation can provide valuable clues for the mechanisms study of local climate $[4,5]$.

At first, precipitation gauge observations were used to study the diurnal variation of precipitation [6-11]. Using hourly precipitation gauge observations from 588 weather stations, Yu et al. [7] analyzed the spatial pattern of diurnal variation of summer precipitation over China. The results show that the prevailing afternoon precipitation is over southern inland China and northeastern China, while the prevailing midnight precipitation is over most of the Tibetan Plateau and its east periphery. Although gauge observations have high accuracy, weather stations are far between. Moreover, diurnal variation of precipitation is various due to the heterogeneities in underlying surface [12, 13]. Accordingly, gauge observations are not sufficient for the study of the spatial pattern of diurnal variation of precipitation.

Recently, the release of abundant satellite-based precipitation data has allowed the use of spatially continuous data to study the diurnal variation of precipitation $[14,15]$. For example, using Tropical Rainfall Measuring Mission (TRMM) data, Nesbitt and Zipser [14] compared the diurnal variation of precipitation over a land area with that over an ocean area and found that the amplitude of diurnal variation of precipitation over the ocean area was less than that over the land area. Although satellite precipitation products are 
usually adjusted by gauge observations, their performance still needs to be improved [16-23]. Previous studies [24-26] have also noted that satellite precipitation products perform poorly at capturing hourly precipitation, causing differences between gauge observations and satellite data in diurnal variation of precipitation.

Comparisons between gauge observations and satellite data on diurnal variation of precipitation have been drawn in previous studies $[27,28]$. For example, by selecting the south China coast as the study area, Zhou et al. [28] found that TRMM and Climate Prediction Center morphing technique (CMORPH) satellite precipitation data showed less morning rainfall and more afternoon rainfall than gauge observations. Differences between gauge observations and satellite data on diurnal variation of precipitation have been found in other areas as well $[29,30]$. In these studies [27-30], predefined regions have usually been used to compare gauge observations with satellite data in these studies with differences between gauge observations and satellite data evident for such region, but the actual spatial pattern of diurnal variation of precipitation from precipitation data remains unclear.

In this study, the $K$-means clustering algorithm is applied to mine the spatial pattern of diurnal variation of precipitation from gauge observations and satellite-based precipitation data. Furthermore, a comparison is drawn between gauge observations and satellite-based precipitation data about diurnal variation of precipitation. The objectives of this study are (1) to analyze the seasonal variability and spatial pattern of diurnal variation of precipitation and (2) to compare the diurnal variation of precipitation indicated by gauge observations with that indicated by satellite-based precipitation data. The diurnal variation of precipitation over the contiguous United States (CONUS) is chosen for study because of its long availability of historical gauge data, and the long availability of historical satellite-based precipitation data of TRMM product is used.

\section{Data Sets and Methodology}

\subsection{Data Sets}

2.1.1. Hourly Precipitation Gauge Observations. The precipitation gauge observations used in this study are derived from the hourly precipitation data (HPD) network (version 1 ). The HPD precipitation data set provides hourly precipitation amount of USA from 1948 to 2017, with local solar time (LST), sourced the NOAA/NWS Fischer-Porter (F\&P) in situ network of precipitation gauges. This network consists of approximately 2,000 stations that are a subset of the NWS Cooperative Observers Program (COOP) network. The data set was compiled and released by the National Centers for Environmental Information (NCEI) and can be freely requested at ftp://ftp.ncdc.noaa.gov/pub/data/hpd/ auto/v1/beta/. A quality control procedure has been applied to the data set based on a paradigm established [31-33].
For this research, precipitation gauge observations were extracted from January 1, 2002, to December 31, 2016. The locations of the 1,243 chosen stations, those found to have less than 5\% missing data, are shown in Figure 1.

2.1.2. TRMM Precipitation Data: 3 B42 Data. The TRMM is a joint mission between the National Aeronautics and Space Administration (NASA) and the Japan Aerospace Exploration Agency (JAXA). The TRMM satellite was launched in 1997 to monitor and study tropical precipitation [34, 35]. The satellite carries three precipitation-relevant instruments: a precipitation radar (PR), TRMM microwave image (TMI), and visible and infrared scanner (VIRS).

The TRMM 34B2 precipitation product (version 7) with 3 -hour temporal resolution and $0.25^{\circ}$ spatial resolution is used here, which can be downloaded from Google Earth Engine (https://explorer.earthengine.google.com/\#index). This product is a multisatellite data set and is created by blending the passive microwave data collected by the TMI, the Special Sensor Microwave Imager, the Advanced Microwave Scanning Radiometer for Earth Observing System, the Advanced Microwave Sounding Unit B, and the IR data $[35,36]$.

To allow comparison with precipitation gauge observations, TRMM grid data were first extracted for each of the 1,243 precipitation gauge stations' locations, dating from January 1, 2002, to December 31, 2016. The extracted data were then interpolated into hourly precipitation data using a $B$-spline interpolation method. Local solar time (LST) was used to calculate hourly rainfall frequency.

\subsection{Methodology}

2.2.1. Representation of Diurnal Variation of Precipitation. Precipitation frequency was used to research diurnal variation of precipitation in this study, as in previous studies [37-39]. First, hourly precipitation frequency was calculated as times of measurable precipitation amounts (i.e., $\geq 0.1 \mathrm{~mm} \mathrm{~h}^{-1}$ ) for each hour, expressed as a 24-dimensional vector corresponding to 24 hours in a day. Then hourly precipitation frequency was normalized using the following formula [40]:

$$
D(h)=\left(\frac{P(h)}{(1 / 24) \sum_{i=1}^{24} P(i)}-1\right),
$$

where $D(h)$ represents the normalized precipitation frequency at time $h$ and $P(h)$ represents the original precipitation frequency at time $h$.

\subsubsection{Mining the Spatial Pattern of Diurnal Variation of} Precipitation. The $K$-means clustering algorithm is applied to mine the spatial pattern of the diurnal variation of precipitation, as previously used to mine the spatial pattern of diurnal rainfall variation over China by Zhu et al. [39]. 


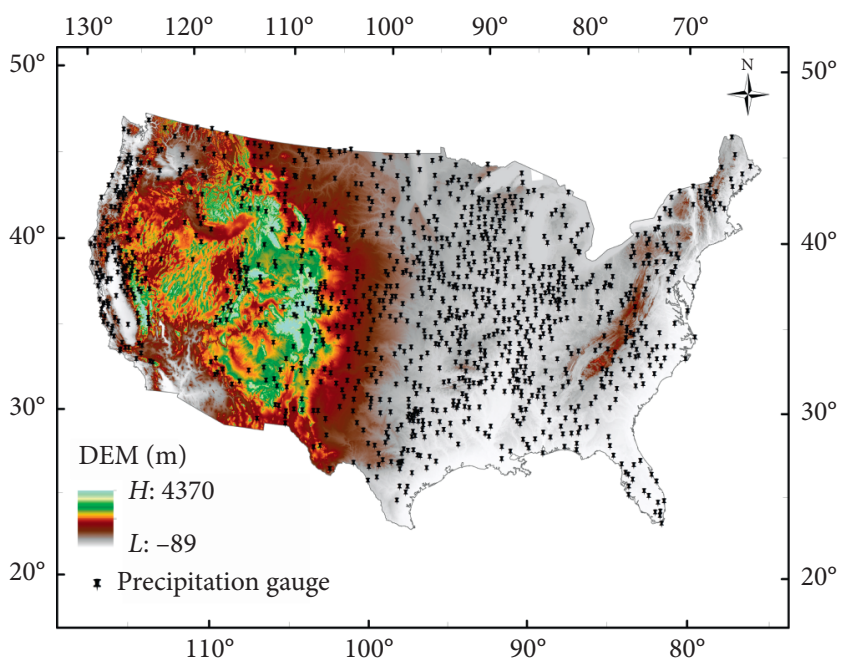

FIGURE 1: Locations of the 1243 precipitation gauge stations and the elevation of the CONUS.

The $K$-means clustering algorithm aims to partition $n$ observations into $K$ clusters such that each observation belongs to the cluster having the nearest distance. The number of clusters ( $K$ values) must be determined in advance. To identify an ideal $K$ number, various $K$ values ranging from 2 to 31 were used for clustering, after which the average distance from every point to its corresponding cluster center was calculated. The average distance decreased with increases in cluster number and the decreased values of average distance were also declining with the increase of the cluster number. A slight drop in average distance caused cluster number to be larger than the "true" number of clusters, so the clusters do not need to be divided any more [41]. Finally, the $20 \mathrm{~K}$ clusters were selected as the ideal $\mathrm{K}$ number in this study.

A large enough cluster number can lead to clusters that have similar diurnal variation of precipitation. Such clusters should be merged manually. Peak time is the most interesting information in the study of diurnal variation of precipitation. Therefore, the merging criteria used here are as follows: Clusters were merged if their peak times of diurnal variation fell into any of six periods: from 0300 LST to 0600 LST (early morning), from 0700 LST to 1000 LST (morning), from 1100 LST to 1400 LST (midday), from 1500 LST to 1800 LST (afternoon), from 1900 LST to 2200 LST (evening), and from 2300 LST to 0200 LST (midnight). For the diurnal variation of precipitation with multiple peaks, clusters were merged only if all peak times were similar. The merging criteria are the same as mentioned above. It should be noted that only if the amplitude of diurnal variation was larger than 0.2 , then it was deemed to be a peak.

2.2.3. Spatial Aggregation Analysis. Moran's index (Moran's I; ranges from -1.0 to +1.0 ) is used to analyze the spatial aggregation of diurnal variation of precipitation. A positive value of Moran's I means that the diurnal variation of precipitation is clustered in space, whereas a negative value means that diurnal variation is discrete in space and a value of zero means that diurnal variation is random in space. $z$-score indicates confidence level. For reference, the $z$-score for $95 \%$ confidence is larger than 1.96 or smaller than -1.96 , and the $z$-score for $99 \%$ confidence is larger than 2.58 or smaller than -2.58 .

\section{Results}

3.1. Diurnal Variation of Precipitation of Gauge Observations. Figure 2 shows stations having different diurnal variation of precipitation of gauge observations in four seasons: Figure 2(a) for spring (March, April, and May), Figure 2(b) for summer (June, July, and August), Figure 2(c) for autumn (September, October, and November), and Figure 2(d) for winter (December, January, and February). The percent of each type of diurnal variation in different season was given in Table 1.

In Figure 2(a), there are 6 types of diurnal variation of precipitation: no peak diurnal variation (not shown in the figures), morning peak diurnal variation, midday peak diurnal variation, afternoon peak diurnal variation, early night peak diurnal variation, and midnight peak diurnal variation. The stations having no peak diurnal variation of precipitation account for $46.8 \%$ of total stations $(1,243)$. Stations having the other five types of diurnal variation of precipitation, morning peak, midday peak, afternoon peak, early night peak, and midnight peak, account for $22.2 \%, 14.2 \%$, $5.6 \%, 10.2 \%$, and $1 \%$ of total stations, respectively.

In Figure 2(b), there are 7 types of diurnal variation of precipitation. An early morning peak diurnal variation is more than that in Figure 2(a). 10.2\% of total stations have no peak diurnal variation of precipitation. Stations having the other six types of diurnal variation account for $35.6 \%$ (morning peak), 3.4\% (midday peak), 24.7\% (afternoon peak), $14.1 \%$ (early night peak), $4.8 \%$ (midnight peak), and $7.2 \%$ (early morning peak).

Figures 2(c) and 2(d) have the same types of diurnal variation of precipitation as in Figure 2(a). In Figure 2(c), $32.8 \%$ of stations have no peak diurnal variation and stations having the other five types of diurnal variation account for 

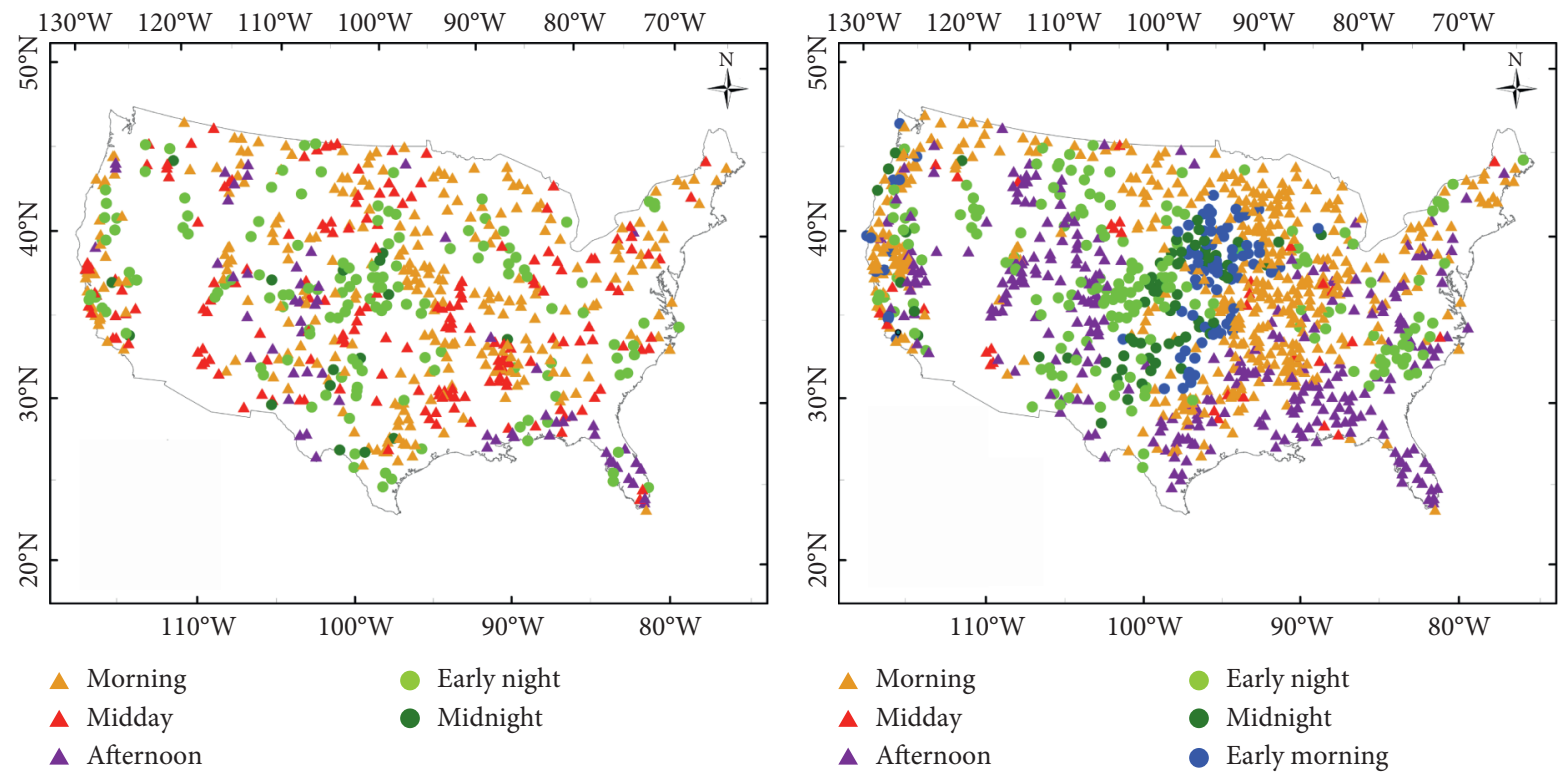

(a)

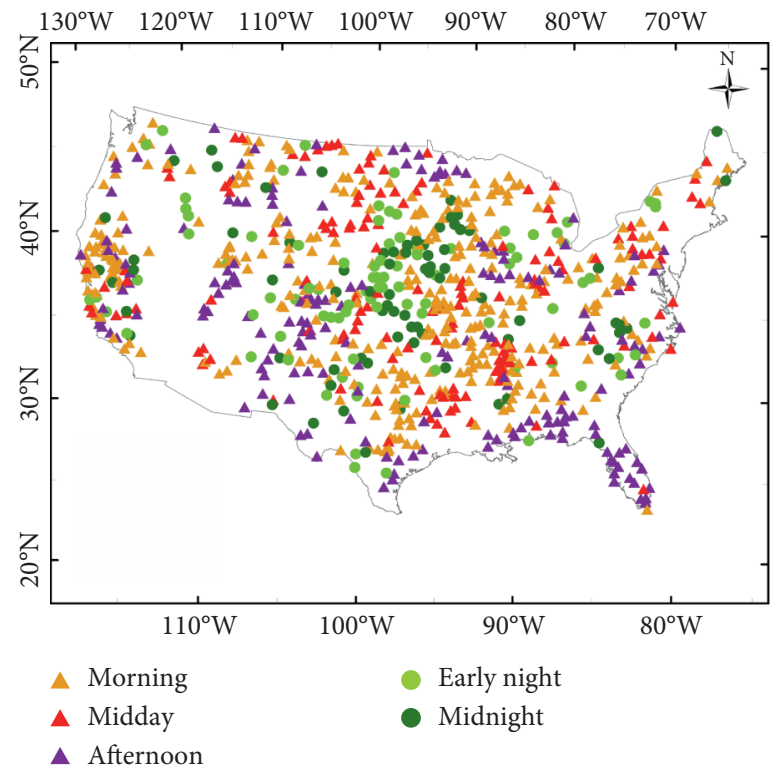

(c)

(b)

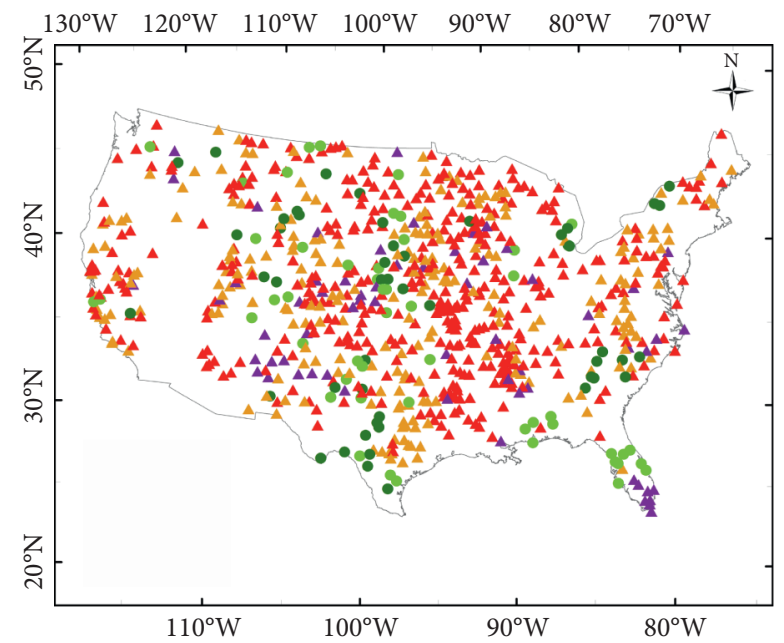
A Morning
- Early night
$\Delta$ Midday
- Midnight
- Afternoon

(d)

Figure 2: Stations with different diurnal variation of precipitation of gauge observations in different seasons: (a) for spring, (b) for summer, (c) for autumn, and (d) for winter. The triangle represents the diurnal variation with day peak, and the circle represents the diurnal variation with night peak.

TABle 1: The percent of different type of diurnal variation in Figure 2 (unit: \%).

\begin{tabular}{lccccccc}
\hline & No peak & Morning & Midday & Afternoon & Early- $N$ & Midnight & Early- $M$ \\
\hline Spring & 47 & 22 & 14 & 5 & 11 & 1 & 0 \\
Summer & 10 & 36 & 3 & 24 & 15 & 7 & 6 \\
Autumn & 33 & 27 & 12 & 15 & 7 & 0 & 6 \\
Winter & 35 & 19 & 33 & 5 & 4 & 4 \\
\hline
\end{tabular}

Early- $N$ is short for early night, and Early- $M$ is short for early morning. 
27.4\% (morning peak), 11.8\% (midday peak), 15\% (afternoon peak), $7.6 \%$ (early night peak), and 5.4\% (midnight peak). In Figure 2(d), 34.9\% of stations have no peak diurnal variation and stations having the other five types of diurnal variation account for $19.3 \%$ (morning peak), 32.8\% (midday peak), 5.2\% (afternoon peak), 4.1\% (early night peak), and $3.7 \%$ (midnight peak). These results show that the spatial pattern of diurnal variation of precipitation of gauge observations presents seasonal variability.

In Figure 2, the stations with different diurnal variation of precipitation present the spatial aggregation characteristics. The phenomenon is particularly obvious in summer (Figure 2(b)). It can be seen from Figure 2(b) that the prevailing high precipitation is mainly located in the central of the CONUS, while the prevailing afternoon precipitation is mainly distributed in the coastal region and the mid-west region of the CONUS. Table 2 summarizes Moran's I and the corresponding $z$-scores for the classified stations in Figure 2. All $z$-scores for the four seasons are much larger than 2.58, indicating that stations having similar diurnal variation of precipitation are significantly clustered in space.

Figure 3 shows the curve of normalized hourly precipitation frequency corresponding to the diurnal variation of precipitation in Figure 2. The amplitudes of the curves in spring, autumn, and winter are comparable but they are much less than that in summer. These results show that the amplitude of diurnal variation of precipitation of gauge observations presents seasonal variability. Similar conclusion was mentioned in a previous study (Dai et al., 1999).

\subsection{Diurnal Variation of Precipitation of TRMM Data.} Figure 4 shows stations having different diurnal variation of precipitation of TRMM data in four seasons: Figure 4(a) for spring, Figure 4(b) for summer, Figure 4(c) for autumn, and Figure 4(d) for winter. The percents of each type of diurnal variation in Figure 4 are given in Table 3.

In Figure 4(a), there are 6 types of diurnal variation of precipitation: no peak diurnal variation, midday peak diurnal variation, afternoon peak diurnal variation, early night peak diurnal variation, midnight peak diurnal variation, and two peaks with one peak in the morning and the other in the afternoon. For these stations, $24.2 \%$ of stations have no peak diurnal variation, and stations having the other five types of diurnal variation account for 3.4\% (midday peak), $24.7 \%$ (afternoon peak), 13.8\% (early night peak), 26.1\% (midnight peak), and $7.8 \%$ (two peaks).

Figures 4(b) and 4(c) have the same types of diurnal variation of precipitation as in Figure 4(a). In Figure 4(b), $9.1 \%$ of stations have no peak diurnal variation of precipitation and stations having the other five types of diurnal variation account for $1.2 \%$ (midday peak), $57.5 \%$ (afternoon peak), $0.6 \%$ (early night peak), 30.0\% (midnight peak), and $1.6 \%$ (two peaks-one in the morning and the other in the afternoon). In Figure 4(c), 55.8\% of stations have no peak diurnal variation of precipitation and stations having the other five types of diurnal variation account for $2.1 \%$ (midday peak), 22.3\% (afternoon peak), 3.1\% (early night peak), $10.8 \%$ (midnight peak), and 5.9\% (two peaks-one in the morning and the other in the afternoon).
In Figure 4(d), stations having no peak diurnal variation of precipitation account for $47.1 \%$ and stations having the other five types of diurnal variation account for $10.8 \%$ (morning peak), $1.6 \%$ (midday peak), $4.2 \%$ (afternoon peak), 32\% (midnight peak), and 4.3\% (two peaks-one in the morning and the other in the afternoon). The result shows that the spatial pattern of diurnal variation of precipitation of TRMM data also presents seasonal variability.

Compared with spatial pattern of diurnal variation of precipitation in Figure 2, the spatial pattern of Figure 4 is more clustered in all seasons than the spatial pattern in Figure 2. It can be seen from Figure 4 that the diurnal variation of precipitation with day peak occurs mostly in the west and the east of the CONUS, whereas the diurnal variation of precipitation with night peak occupies the middle area of the CONUS. In the southeastern CONUS, the diurnal variation of precipitation with afternoon peak is predominant over this area in spring, summer, and autumn. Table 4 summarizes Moran's I and corresponding $z$-scores for the diurnal variation of precipitation in Figure 4. Moran's I indexes in Table 4 are larger than those in Table 2 in four seasons. The result indicates that the spatial pattern of diurnal variation of precipitation of TRMM data also is significantly clustered in space.

Similarly, Figure 5 shows the curve of normalized hourly TRMM precipitation frequency. The amplitudes of the curves in spring, autumn, and winter are comparable and are less than that in summer. In addition, a new diurnal variation of precipitation, with one peak in morning and the other in the afternoon, appears in four seasons. The results show that the amplitude of diurnal variation of precipitation of TRMM data presents seasonal variability.

\section{Discussion}

4.1. Difference of Diurnal Variation of Precipitation between Gauge Observations and TRMM Data. According to the classification of diurnal variation of precipitation in Figure 2 (gauge observations), this study calculated the normalized hourly TRMM precipitation frequency for each type of diurnal variation of precipitation (shown in Figure 6). As shown in Figure 6, stations that had prevailing afternoon precipitation in gauge observations still had an afternoon peak in TRMM data. However, stations that had other types of diurnal variation of precipitation in gauge observations had different types of diurnal variation of precipitation in TRMM data.

Similarly, according to the classification of diurnal variation of precipitation in Figure 4 (TRMM data), this study calculated the normalized hourly gauge precipitation frequency for each type of diurnal variation of precipitation (shown in Figure 7). The curves in Figure 7 show that stations that had an afternoon peak in TRMM data still had an afternoon peak in gauge observations but that stations that had other types of diurnal variation of precipitation had different types of diurnal variation of precipitation in gauge observations.

In general, precipitation gauge observations can be regarded as the true value, and TRMM data should be the 
TABLE 2: Moran's I and the $z$-scores for the diurnal variation of precipitation in Figure 2.

\begin{tabular}{lcccc}
\hline & Spring & Summer & Autumn & Winter \\
\hline Moran's I & 0.22 & 0.30 & 0.19 & 0.25 \\
$z$-score & 21.8 & 28.6 & 19.2 & 25.3 \\
\hline
\end{tabular}

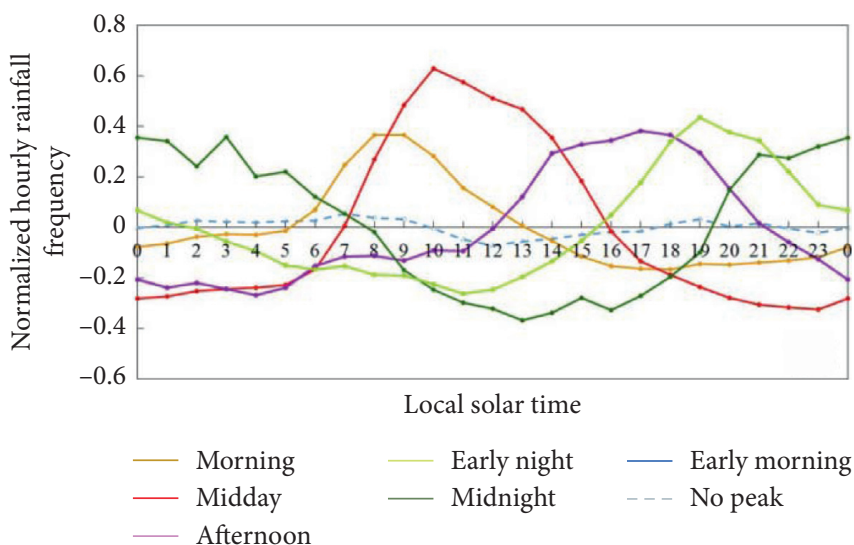

(a)

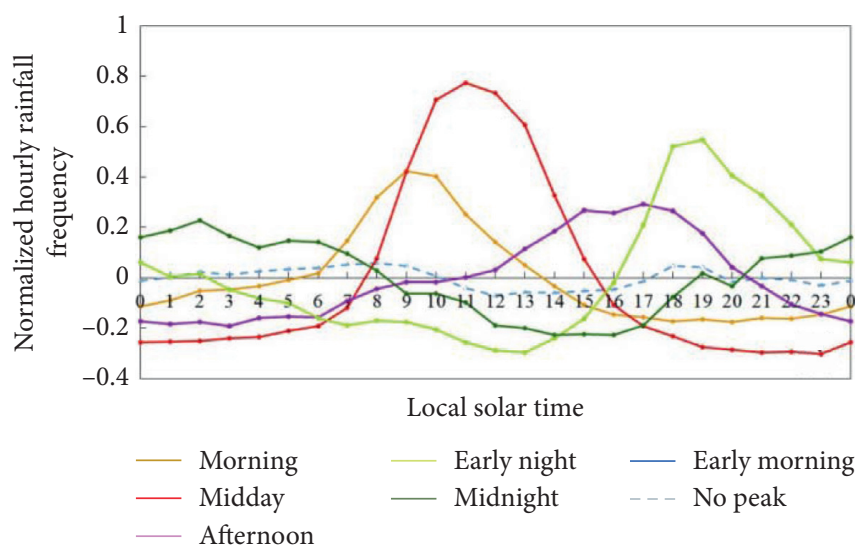

(c)

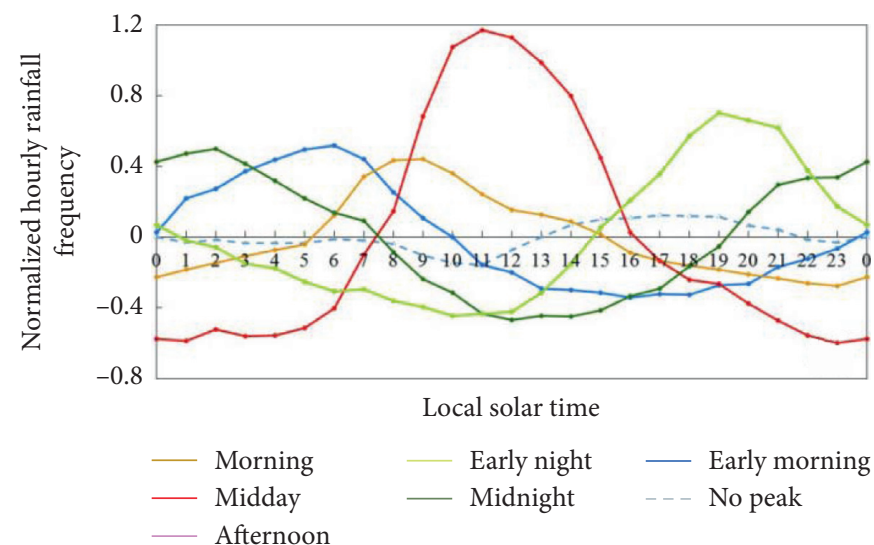

(b)

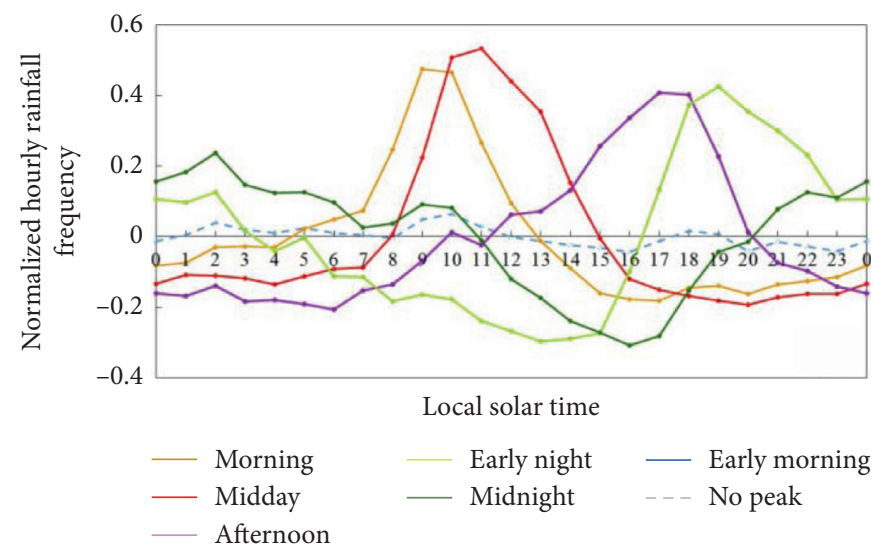

(d)

FIGURE 3: Curve of normalized hourly precipitation frequency corresponding to each type of diurnal variation of precipitation in Figure 2: (a) for spring, (b) for summer, (c) for autumn, and (d) for winter.

same as gauge observations in theory. However, as shown in Figures 6 and 7, except for prevailing afternoon precipitation, diurnal variation of precipitation in gauge observations was largely inconsistent with TRMM data, indicating that TRMM data can well capture prevailing afternoon precipitation but performs poorly at capturing hourly precipitation at other times. A study by Kotsifakis et al. [42] also pointed out that version 7 of the TRMM 3 B 42 precipitation data can hardly captain the characteristics of 3-hour, 6-hour, 12-hour, 24-hour, and 48-hour precipitation. The result obtained in this study further confirms the conclusion that the TRMM $3 \mathrm{~B} 42$ data performs poorly in captaining the characteristics of hourly precipitation.
4.2. Possible Mechanism behind Prevailing Nocturnal Precipitation. Prevailing nocturnal precipitation over the middle of the CONUS has been explained by the mountainplains solenoid (MPS) circulation in previous studies $[6,43-45]$. The obtained results of this study can provide valuable clues for studying the mechanism of diurnal variation of precipitation.

As shown in Figures 2 and 4, prevailing nocturnal precipitation occurs mostly in the middle of the CONUS. This phenomenon is more obvious in summer than in other seasons. Taking six stations with prevailing nocturnal precipitation in summer as an example (shown in Figure 8), the possible mechanism behind the prevailing nocturnal precipitation is discussed. 


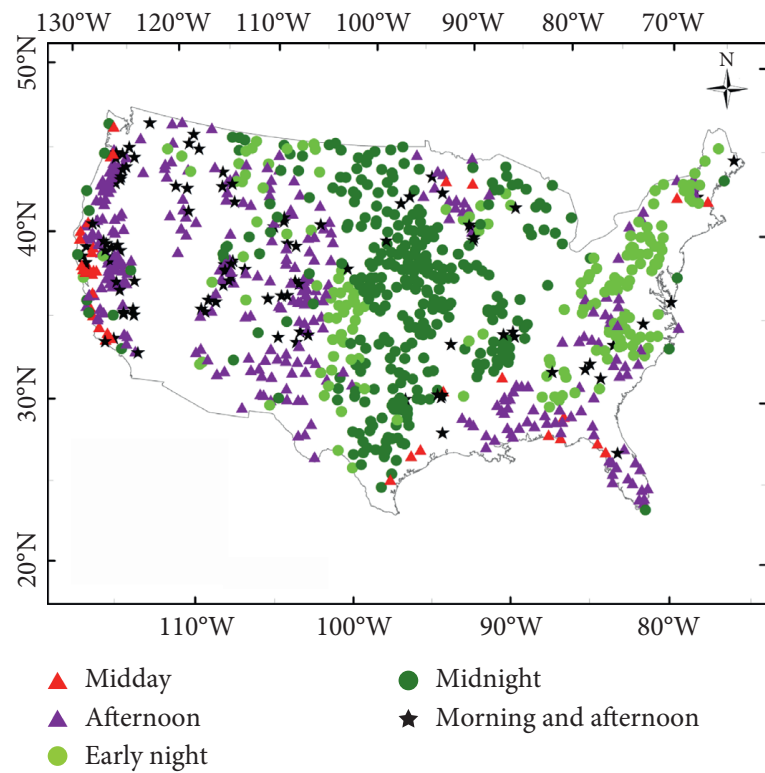

(a)

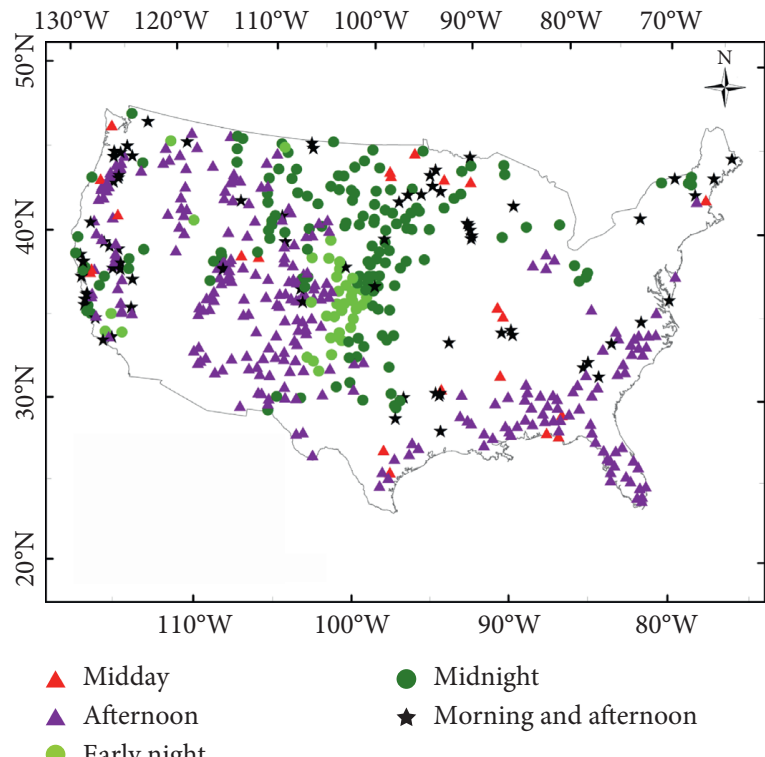

(c)

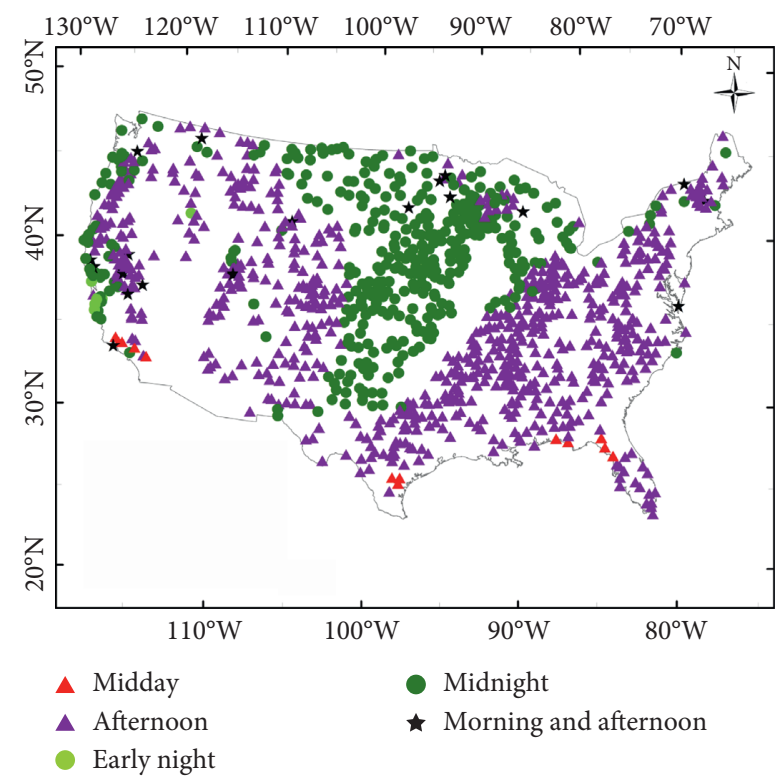

(b)

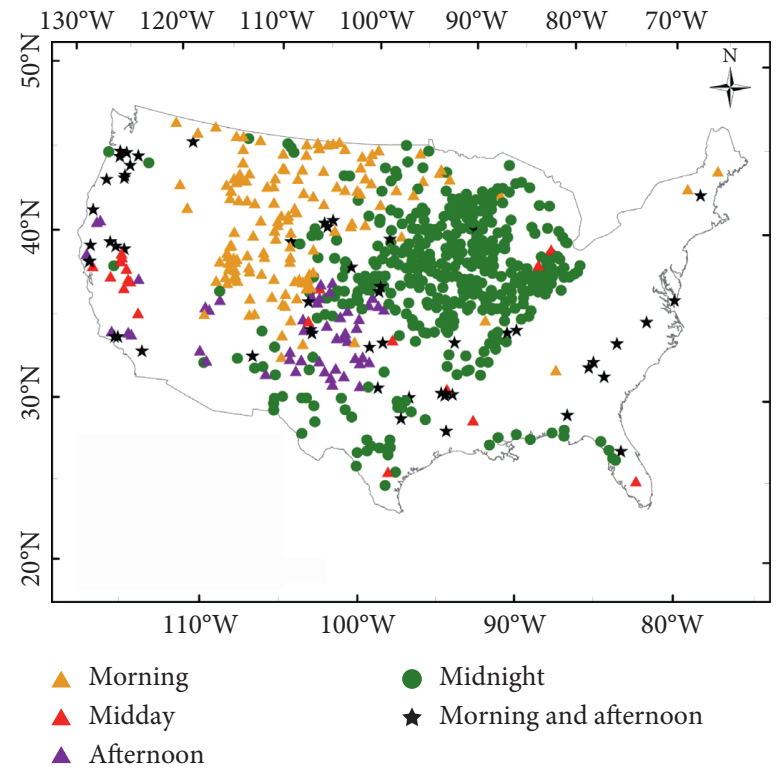

(d)

FIGURE 4: Stations with different diurnal variation of precipitation of TRMM data in different seasons: (a) for spring, (b) for summer, (c) for autumn, and $(\mathrm{d})$ for winter. The triangle represents the diurnal variation with day peak, and the circle represents the diurnal variation with night peak.

Figure 8(a) shows the locations of the six stations, and the elevation profile line along the six stations is shown in Figure $8(\mathrm{~b})$. As can be seen, the six stations are mainly distributed in the transitional area, from mountain area to plain area. Figures $8(\mathrm{c})$ and $8(\mathrm{~d})$ show the curves of normalized hourly precipitation frequency for gauge observations and TRMM data, respectively. As shown in Figure 8(c), the diurnal variation of precipitation at Stations A, B, and C has an early night peak, whereas early morning precipitation predominates at Stations D and $\mathrm{E}$ and the diurnal variation of precipitation at Station $\mathrm{F}$ has a morning peak. The peak time of diurnal variation at these six stations presents eastward delay from Station A to Station F. This phenomenon can also be found in TRMM data (Figure 8(d)).

For MPS circulation, the cold air mass over mountains flows along the slope of mountains to the plains due to the stronger surface cooling on the mountains compared to that on the plains at night $[39,46]$. Then the downward movement of cold air mass lifts the warm air mass at the downslope of mountains, which causes atmospheric instability and leads to prevailing nocturnal precipitation [47]. As the enhanced cooling air mass in deep night, it will strengthen the propagation of flow from mountaintop to plains. Then the further warm air mass is lifted, causing 
TABLE 3: The percent of different types of diurnal variation in Figure 4 (unit: \%).

\begin{tabular}{|c|c|c|c|c|c|c|c|}
\hline & No peak & Morning & Midday & Afternoon & Early- $N$ & Midnight & Early- $M$ \\
\hline Spring & 24 & 0 & 3 & 25 & 14 & 26 & 8 \\
\hline Summer & 9 & 0 & 1 & 58 & 0.5 & 30 & 1.5 \\
\hline Autumn & 56 & 0 & 2 & 22 & 3 & 11 & 6 \\
\hline Winter & 47 & 11 & 1.5 & 4 & 0 & 32 & 4.5 \\
\hline
\end{tabular}

Early- $N$ is short for early night, and Early- $M$ is short for early morning.

TABLE 4: Moran's I and the $z$-scores for the diurnal variation of precipitation in Figure 4.

\begin{tabular}{lcccc}
\hline & Spring & Summer & Autumn & Winter \\
\hline Moran's I & 0.47 & 0.50 & 0.39 & 0.50 \\
$z$-score & 46.4 & 50.1 & 39.1 & 49.6 \\
\hline
\end{tabular}

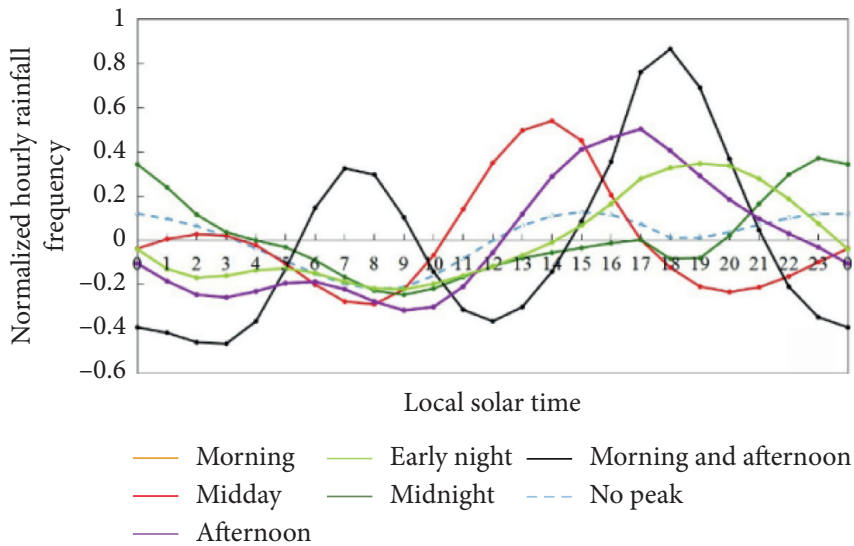

(a)

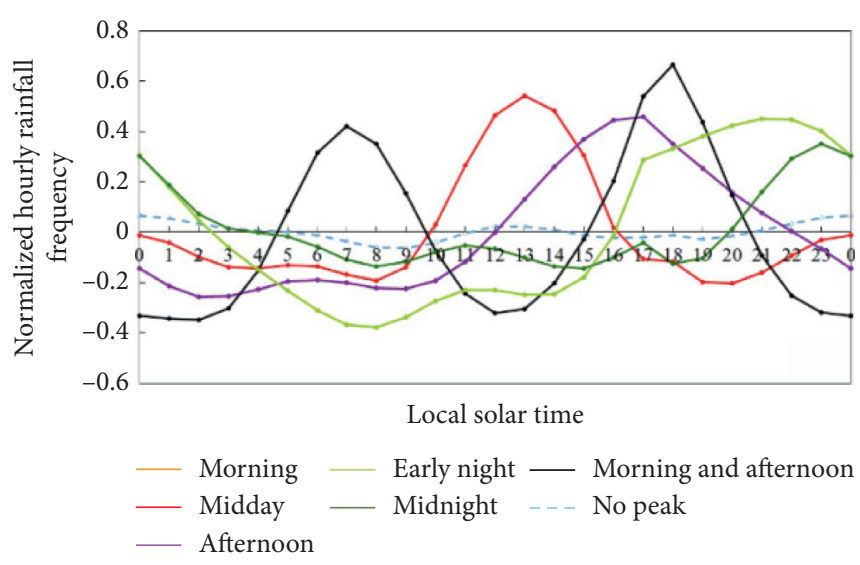

(c)

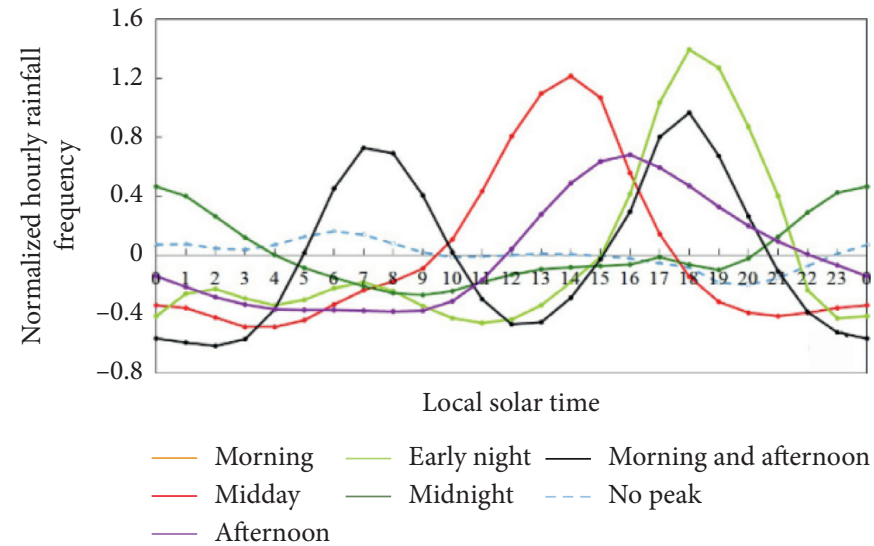

(b)

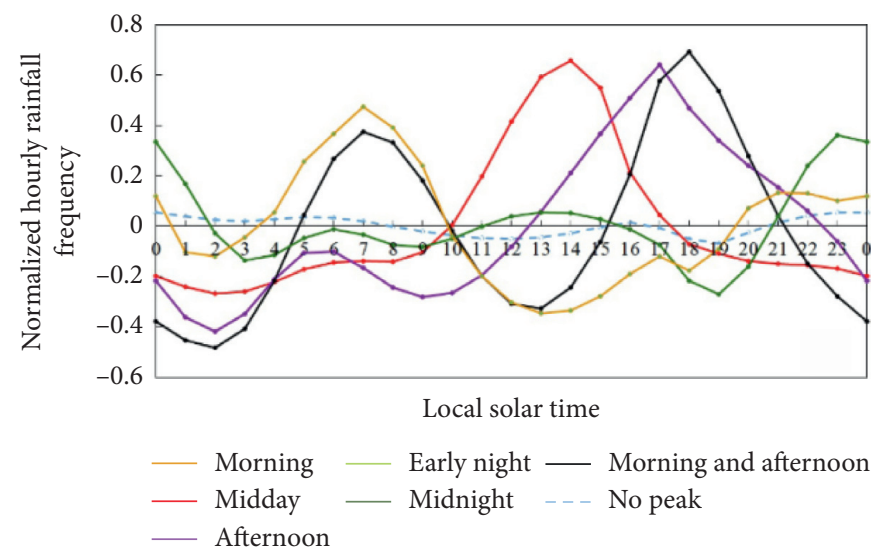

(d)

FIGURE 5: Curve of normalized hourly precipitation frequency corresponding to each type of diurnal variation in Figure 4: (a) for spring, (b) for summer, (c) for autumn, and (d) for winter.

prevailing nocturnal precipitation. The nocturnal rain belt moves accordingly, causing a time-delay pattern of rainfall peaks along the slope of macroterrain.

However, Seo et al. [48] and Seo et al. [49] also found anomalous propagation of the prevailing nocturnal precipitation over the middle of the CONUS using radarrainfall data. However, in their study, the anomalous propagation of the prevailing nocturnal precipitation was attributed to wind turbines' interference in radar observations. Wind turbines are clustered to form wind farms at night, leading to prevailing nocturnal precipitation in radar observations.

It should be noted that the mechanism of diurnal variation of precipitation is complicated [50-52]. The formation of diurnal variation of precipitation is affected by many factors, such as solar radiation, complex terrain, multiscale 


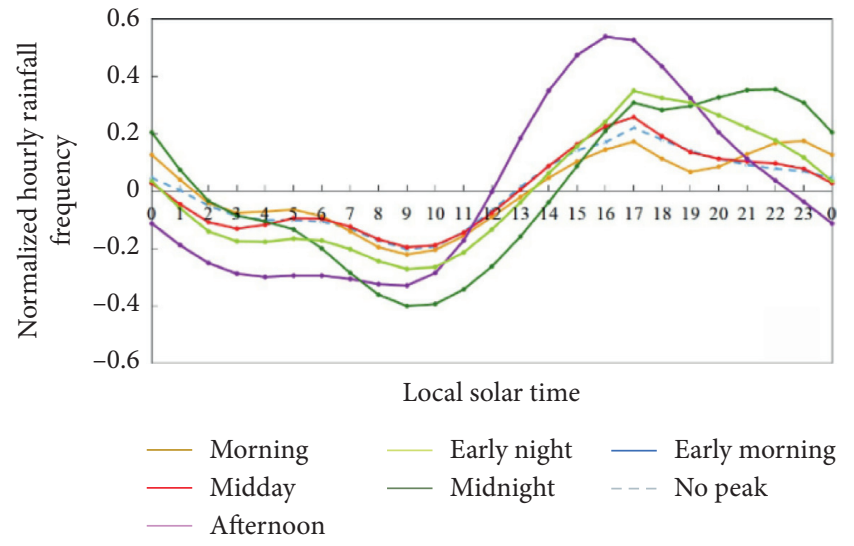

(a)

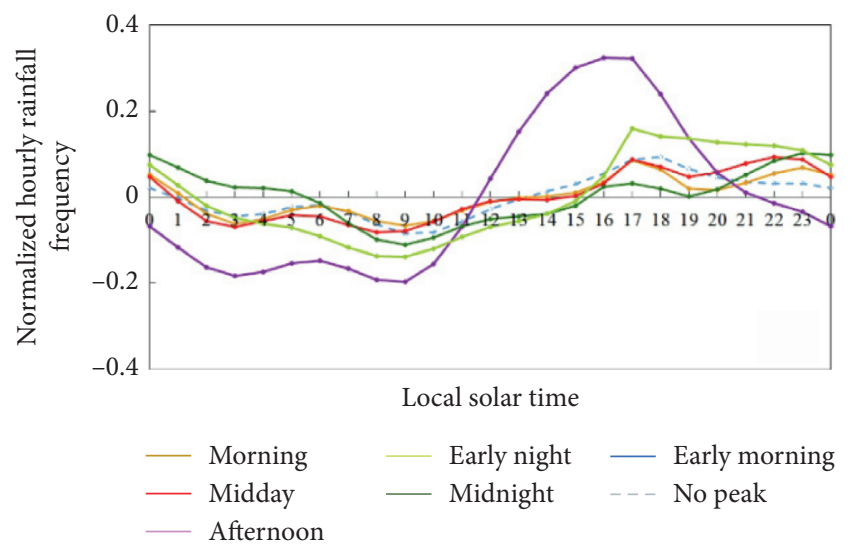

(c)

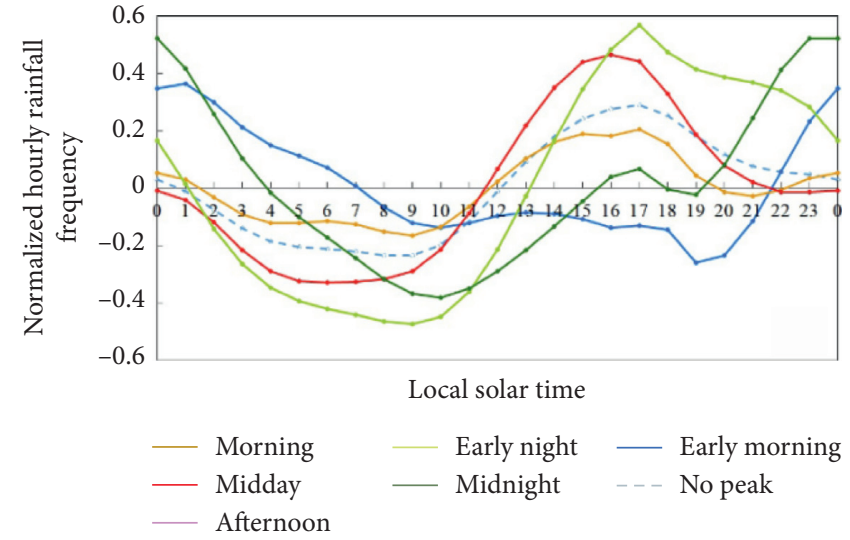

(b)

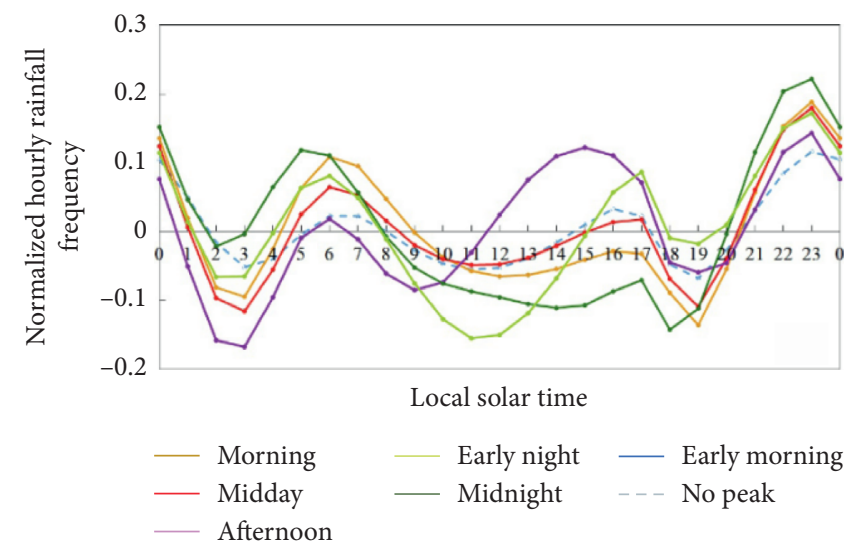

(d)

FIGURE 6: Curves of normalized hourly TRMM precipitation frequency, calculated based on the classification of diurnal variation of precipitation in Figure 2: (a) for spring, (b) for summer, (c) for autumn, and (d) for winter.

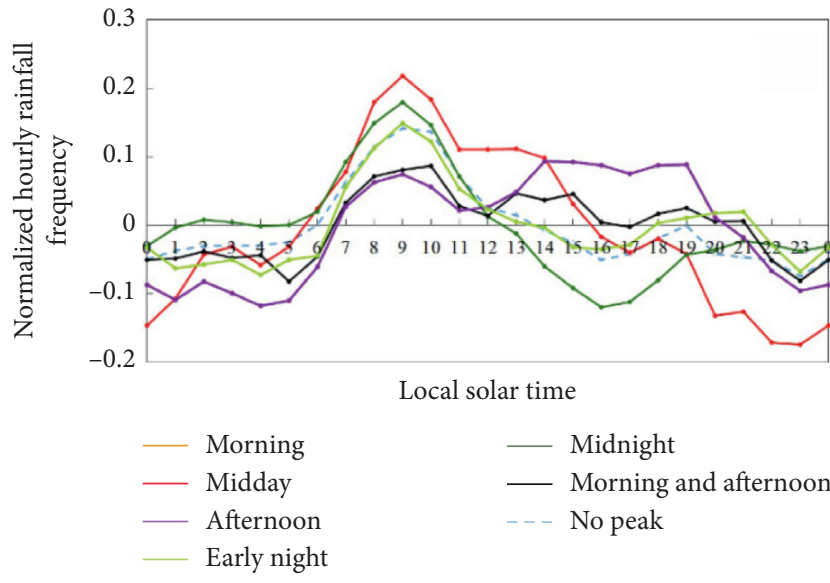

(a)

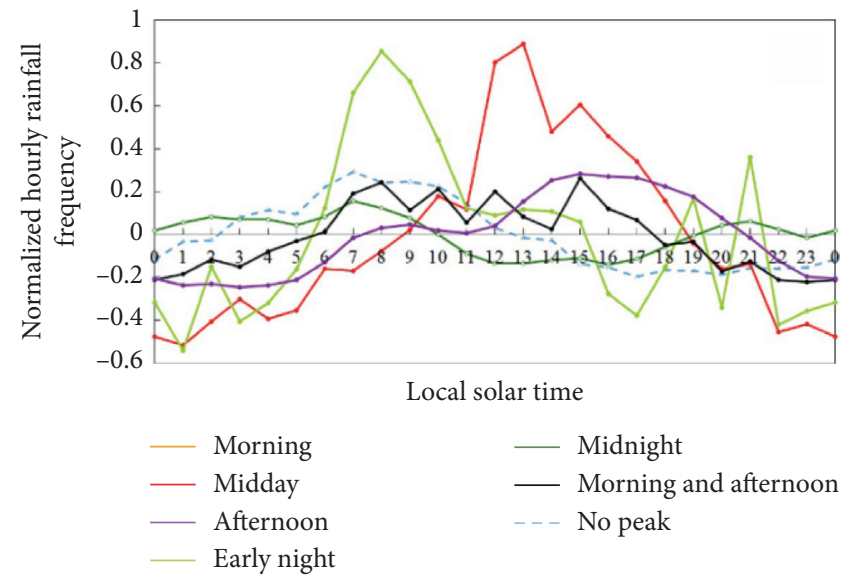

(b)

FIgURe 7: Continued. 


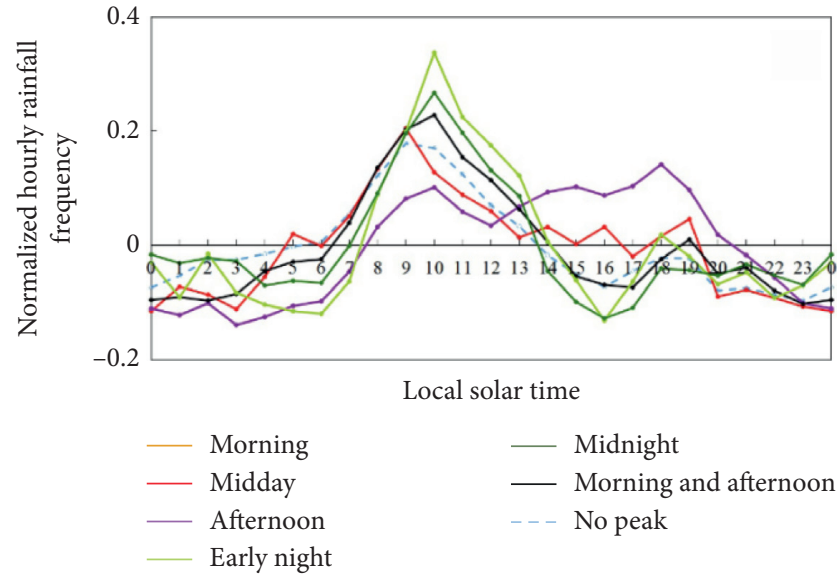

(c)

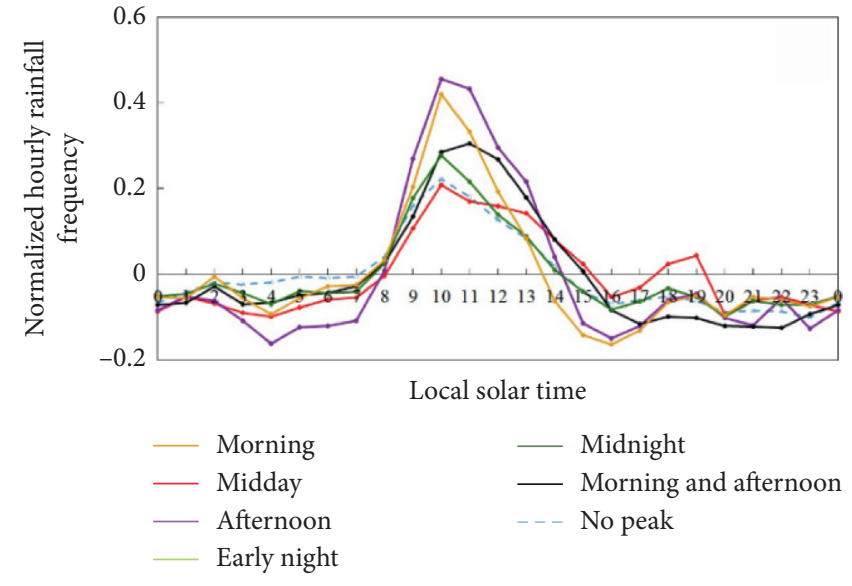

(d)

FIGURE 7: Curves of normalized hourly gauge precipitation frequency, calculated based on the classification of diurnal variation of precipitation in Figure 4: (a) for spring, (b) for summer, (c) for autumn, and (d) for winter.

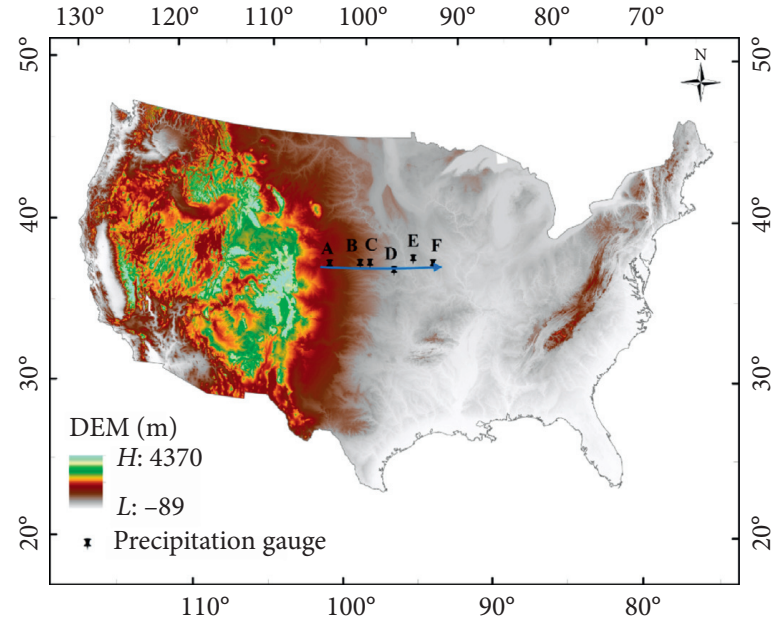

(a)

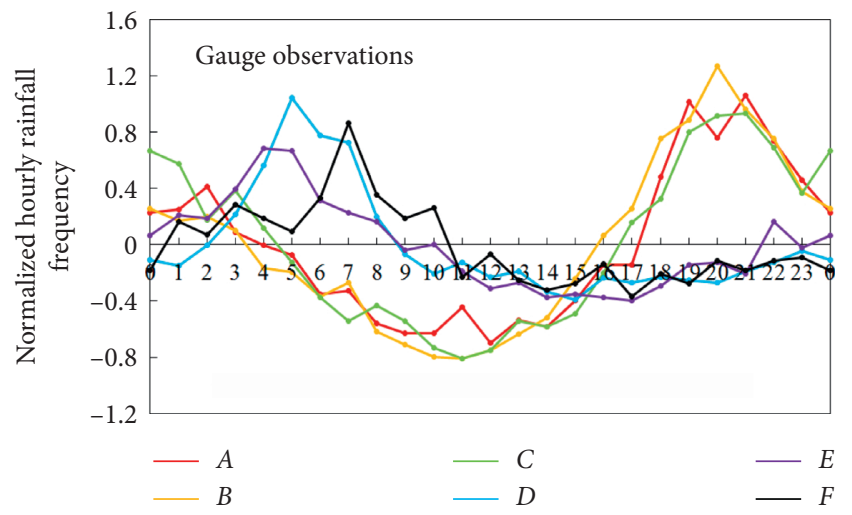

(c)

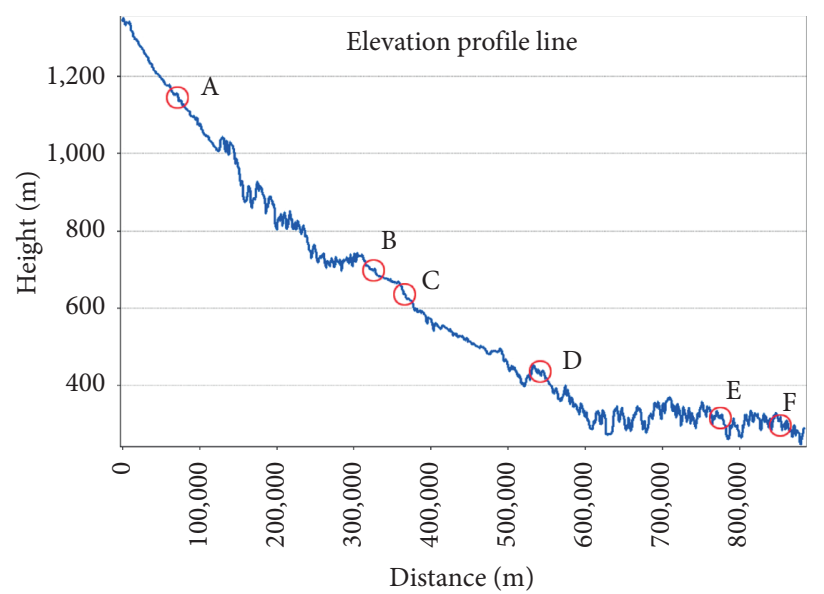

(b)

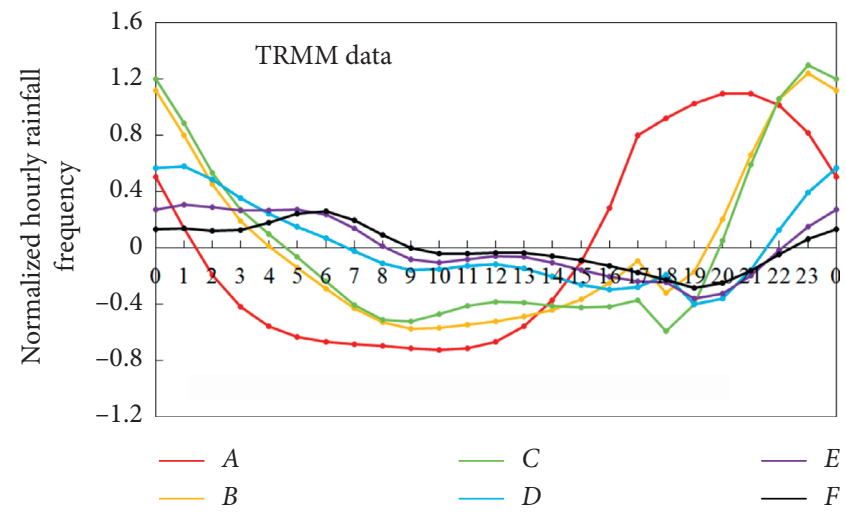

FIGURE 8: (a) Locations of the six precipitation gauge stations. (b) Elevation profile line along the six stations, with directional indicator arrow. (c) Curves of normalized hourly gauge precipitation frequency. (d) Curves of normalized hourly TRMM precipitation frequency. 
atmospheric circulations, and transfer of water vapor $[17,27,29]$. However, one dominant factor in an area usually leads to a peculiar diurnal variation of precipitation. For example, the prevailing day precipitation is usually caused by surface solar heating $[37,53]$, whereas prevailing midnight precipitation and the prevailing early morning precipitation are usually related to complex terrain or sea-breeze circulations $[53,54]$.

This study focuses on spatial and seasonal patterns of diurnal variation of precipitation, comparing the diurnal variation of precipitation in gauge observations with that in satellite data. The mechanism study for diurnal variation of precipitation is a vast topic beyond the scope of this study, which focuses on analyzing the possible mechanism behind the prevailing nocturnal precipitation over the middle of the CONUS. Detailed mechanisms for diurnal variation of precipitation over the CONUS require further study, but the results of this study can provide valuable clues for the studies of the mechanism involved.

\section{Conclusion}

Diurnal variation of precipitation is a fundamental periodic signal of local climate. The study of diurnal variation of precipitation is helpful in studying the formation of local climate and validating satellite precipitation products. Precipitation gauge observations and satellite-based precipitation data were both used to study the diurnal variation of precipitation in previous studies. However, the diurnal variation of precipitation obtained from gauge observations is usually inconsistent with that obtained from satellite-based data due to the poor performance satellite-based precipitation data. Besides, predefined regions have usually been used to compare gauge observations with satellite data in these studies with differences between gauge observations and satellite data, but the actual spatial pattern of diurnal variation of precipitation from precipitation data remains unclear.

In this study, a comparison was drawn between precipitation gauge observations and TRMM data concerning diurnal variation of seasonal precipitation. The following conclusions were drawn:

(1) Diurnal variation of precipitation over the CONUS presents seasonal variability.

(2) Diurnal variation of precipitation shows clustered features in space but with significant differences in spatial pattern between mapped gauge observations and mapped TRMM data.

(3) TRMM data can capture the prevailing afternoon precipitation well but perform poorly at capturing hourly precipitation at other times.

(4) Prevailing nocturnal precipitation over the middle of the CONUS seems to be related to MPS circulation.

\section{Data Availability}

The [TRMM] data used to support the findings of this study have been deposited in Google Earth Engine repository [https:// explorer.earthengine.google.com/\#index]. The [hourly precipitation gauge observations] data used to support the findings of this study have been deposited in the the National Centers for Environmental Information (NCEI) repository [ftp://ftp.ncdc. noaa.gov/pub/data/hpd/auto/v1/beta/].

\section{Conflicts of Interest}

The authors declare that there are no conflicts of interest regarding the publication of this paper.

\section{Acknowledgments}

This work was supported by the Postdoctoral Research Funding Program of Jiangsu Province (Grant no. 2020Z223), the National Natural Science Foundation of China (Grant no. 41771478), and the Fundamental Research Funds for the Central Universities (Grant no. 2019B02514).

\section{References}

[1] A. Dai, "Global precipitation and thunderstorm frequencies. Part II: diurnal variations," Journal of Climate, vol. 14, no. 6, pp. 1112-1128, 2001.

[2] W. Yuan, R. Yu, H. Chen, J. Li, and M. Zhang, "Subseasonal characteristics of diurnal variation in summer monsoon rainfall over central eastern China," Journal of Climate, vol. 23, no. 24, pp. 6684-6695, 2010.

[3] J. Li, T. Chen, and N. Li, "Diurnal variation of summer precipitation across the central tian Shan mountains," Journal of Applied Meteorology and Climatology, vol. 56, no. 6, pp. 1537-1550, 2017.

[4] H. Zhang, X. Yan, Z. Cai, and Y. Zhang, "Effect of rainfall on the diurnal variations of $\mathrm{CH}_{4}, \mathrm{CO}_{2}$, and $\mathrm{N}_{2} \mathrm{O}$ fluxes from a municipal solid waste landfill," Science of the Total Environment, vol. 442, pp. 73-76, 2013.

[5] M. Kavitha, P. R. Nair, I. A. Girach, S. Aneesh, S. Sijikumar, and R. Renju, "Diurnal and seasonal variations in surface methane at a tropical coastal station: role of mesoscale meteorology," Science of the Total Environment, vol. 631-632, pp. 1472-1485, 2018.

[6] W. D. Bonner, "Climatology of the low level jet," Monthly Weather Review, vol. 96, no. 12, pp. 833-850, 1968.

[7] M. G. Landin and L. F. Bosart, "Diurnal variability of precipitation in the northeastern United States," Monthly Weather Review, vol. 113, no. 6, pp. 989-1014, 1985.

[8] R. C. Yu, T. J. Zhou, A. Y. Xiong et al., "Diurnal variations of summer precipitation over contiguous China," Geophysical Research Letters, vol. 34, no. 1, pp. 223-234, 2007.

[9] J. Wang, R. Zhang, and Y. Wang, "Areal differences in diurnal variations in summer precipitation over Beijing metropolitan region," Theoretical and Applied Climatology, vol. 110, no. 3, pp. 395-408, 2012.

[10] L. M. D. S. Tanaka, P. Satyamurty, and L. A. T. Machado, "Diurnal variation of precipitation in Central Amazon Basin," International Journal of Climatology, vol. 34, no. 13, pp. 3574-3584, 2014.

[11] X. Li, N.-C. Lau, and T.-C. Lee, "An observational study of the diurnal variation of precipitation over Hong Kong and the underlying processes," Journal of Applied Meteorology and Climatology, vol. 57, no. 6, pp. 1385-1402, 2018. 
[12] X. Bao, F. Zhang, and J. Sun, "Diurnal variations of warmseason precipitation east of the Tibetan plateau over China," Monthly Weather Review, vol. 139, no. 9, pp. 2790-2810, 2011.

[13] A. Wootten, S. Raman, and A. Sims, "Diurnal variation of precipitation over the Carolina Sandhills region," Journal of Earth System Science, vol. 119, no. 5, pp. 579-596, 2010.

[14] S. W. Nesbitt and E. J. Zipser, "The diurnal cycle of rainfall and convective intensity according to three years of TRMM measurements," Journal of Climate, vol. 16, no. 10, pp. 1456-1475, 2003.

[15] G. Chen, W. Sha, and T. Iwasaki, "Diurnal variation of precipitation over southeastern China: spatial distribution and its seasonality," Journal of Geophysical Research, vol. 114, no. D13, pp. 267-275, 2009.

[16] Z. E. Asong, S. Razavi, H. S. Wheater, and J. S. Wong, "Evaluation of integrated multisatellite retrievals for GPM (IMERG) over Southern Canada against ground precipitation observations: a preliminary assessment," Journal of Hydrometeorology, vol. 18, no. 4, pp. 1033-1050, 2017.

[17] G. Chen, R. Lan, W. Zeng, H. Pan, and W. Li, "Diurnal variations of rainfall in surface and satellite observations at the monsoon coast (South China)," Journal of Climate, vol. 31, no. 5, pp. 1703-1724, 2018.

[18] A. T. Haile, E. Habib, and T. Rientjes, "Evaluation of the climate prediction center (CPC) morphing technique (CMORPH) rainfall product on hourly time scales over the source of the Blue Nile River," Hydrological Processes, vol. 27, no. 12, pp. 1829-1839, 2013.

[19] J. Rozante, D. Vila, J. Barboza Chiquetto, A. Fernandes, and D. Souza Alvim, "Evaluation of TRMM/GPM blended daily products over Brazil," Remote Sensing, vol. 10, no. 6, pp. 882-17, 2018.

[20] P. P. Xie and A. Y. Xiong, "A conceptual model for constructing high-resolution gauge-satellite merged precipitation analyses," Journal of Geophysical Research-Atmospheres, vol. 116, no. D21, pp. 1-14, 2011.

[21] Y. Shen, P. Zhao, Y. Pan et al., "A high spatiotemporal gaugesatellite merged precipitation analysis over China," Journal of Geophysical Research-Atmospheres, vol. 119, no. 6, pp. 30633075, 2014.

[22] Q. H. Sun, C. Y. Miao, Q. Y. Duan et al., "A Review of Global Precipitation Data Sets: Data Sources, Estimation, and Intercomparisons," Reviews of Geophysics, vol. 56, no. 1, pp. 79-107, 2018.

[23] D. A. Zeweldi and M. Gebremichael, "Evaluation of CMORPH precipitation products at fine space-time scales," Journal of Hydrometeorology, vol. 10, no. 1, pp. 300-307, 2009.

[24] Z. Duan, J. Liu, Y. Tuo, G. Chiogna, and M. Disse, "Evaluaation of eight high spatial resolution gridded precipitation products in Adige Basin (Italy) at multiple temporal and spatial scales," Science of the Total Environment, vol. 573, pp. 1536-1553, 2016.

[25] E. Sharifi, R. Steinacker, and B. Saghafian, "Multi time-scale evaluation of high-resolution satellite-based precipitation products over northeast of Austria," Atmospheric Research, vol. 206, pp. 46-63, 2018.

[26] M. T. Mahmoud, M. A. Al-Zahrani, and H. O. Sharif, "Assessment of global precipitation measurement satellite products over Saudi Arabia," Journal of Hydrology, vol. 559, pp. 1-12, 2018.

[27] T. Zhou, R. Yu, H. Chen, A. Dai, and Y. Pan, "Summer precipitation frequency, intensity, and diurnal cycle over China: a comparison of satellite data with rain gauge observations," Journal of Climate, vol. 21, no. 16, pp. 3997-4010, 2008.

[28] C. Chen, Q. Chen, Z. Duan et al., "Multiscale comparative evaluation of the GPM IMERG v5 and TRMM 3B42 v7 precipitation products from 2015 to 2017 over a climate transition area of China," Remote Sensing, vol. 10, no. 6, pp. 944-18, 2018.

[29] W. Yuan, R. Yu, M. Zhang, W. Lin, H. Chen, and J. Li, "Regimes of diurnal variation of summer rainfall over subtropical East Asia," Journal of Climate, vol. 25, no. 9, pp. 3307-3320, 2012.

[30] J. Guo, P. Zhai, L. Wu et al., "Diurnal variation and the influential factors of precipitation from surface and satellite measurements in Tibet," International Journal of Climatology, vol. 34, no. 9, pp. 2940-2956, 2014.

[31] R. F. Adler, G. J. Huffman, A. Chang et al., "The version-2 global precipitation climatology project (GPCP) monthly precipitation analysis (1979-present)," Journal of Hydrometeorology, vol. 4, no. 6, pp. 1147-1167, 2003.

[32] I. Durre, M. J. Menne, and R. S. Vose, "Strategies for evaluating quality assurance procedures," Journal of Applied Meteorology and Climatology, vol. 47, no. 6, pp. 1785-1791, 2008.

[33] I. Durre, M. J. Menne, B. E. Gleason, T. G. Houston, and R. S. Vose, "Comprehensive automated quality assurance of daily surface observations," Journal of Applied Meteorology and Climatology, vol. 49, no. 8, pp. 1615-1633, 2010.

[34] G. J. Huffman, "Estimates of root-mean-square random error for finite samples of estimated precipitation," Journal of Applied Meteorology, vol. 36, no. 9, pp. 1191-1201, 1997.

[35] G. Huffman, R. Adler, D. Bolvin et al., The TRMM MultiSatellite Precipitation Analysis (TMPA), Springer, Dordrecht, Netherlands, 2010.

[36] M. S. K. Kiany, R. C. Balling, R. S. Cerveny et al., "Diurnal variations in seasonal precipitation in Iran from TRMM measurements," Advances in Space Research, vol. 62, no. 9, pp. 2418-2430, 2018.

[37] X. Chen, K. Zhao, M. Xue, B. Zhou, X. Huang, and W. Xu, "Radar-observed diurnal cycle and propagation of convection over the Pearl River Delta during Mei-Yu season," Journal of Geophysical Research: Atmospheres, vol. 120, no. 24, pp. 12557-12575, 2015.

[38] X. Jin, T. Wu, and L. Li, "The quasi-stationary feature of nocturnal precipitation in the Sichuan Basin and the role of the Tibetan Plateau," Climate Dynamics, vol. 41, no. 3-4, pp. 977-994, 2012.

[39] L. Zhu, J. Liu, A.-X. Zhu, M. Sheng, and Z. Duan, "Spatial distribution of diurnal rainfall variation in summer over China," Journal of Hydrometeorology, vol. 19, no. 4, pp. 667-678, 2018.

[40] R. Yu, Y. Xu, T. Zhou, and J. Li, "Relation between rainfall duration and diurnal variation in the warm season precipitation over Central Eastern China," Geophysical Research Letters, vol. 34, no. 13, 2007.

[41] R. Anand and D. U. Jeffrey, Mining of Massive Datasets, p. 236, Cambridge University Press, Cambridge, UK, 2011.

[42] K. Kotsıfakıs, E. Felonı, V. Kotronı et al., "Evaluation of the version 7 TRMM multi-satellite precipitation analysis (TMPA) 3B42 product over Greece," in Proceedings of the 15th International Conference on Environmental Science and Technology, Rhodes, Greece, August 2017.

[43] P. G. Wolyn and T. B. McKee, "The mountain-plains circulation East of a 2-km-high North-South barrier," Monthly Weather Review, vol. 122, no. 7, pp. 1490-1508, 1994. 
[44] R. E. Carbone and J. D. Tuttle, "Rainfall occurrence in the U.S. warm season: the diurnal cycle*," Journal of Climate, vol. 21, no. 16, pp. 4132-4146, 2008.

[45] B. Pu and R. E. Dickinson, "Diurnal spatial variability of great plains summer precipitation related to the dynamics of the low-level jet," Journal of the Atmospheric Sciences, vol. 71, no. 5, pp. 1807-1817, 2014.

[46] X. H. Bao and F. Q. Zhang, "Impacts of the mountain-plains solenoid and cold pool dynamics on the diurnal variation of warm-season precipitation over Northern China," Atmospheric Chemistry and Physics, vol. 13, no. 14, pp. 6965-6982, 2013.

[47] Y. Zhang, J. Sun, and S. Fu, "Impacts of diurnal variation of mountain-plain solenoid circulations on precipitation and vortices east of the Tibetan Plateau during the Mei-Yu season," Advances in Atmospheric Sciences, vol. 31, no. 1, pp. 139-153, 2013.

[48] B.-C. Seo, W. F. Krajewski, and K. V. Mishra, "Using the new dual-polarimetric capability of WSR-88D to eliminate anomalous propagation and wind turbine effects in radarrainfall," Atmospheric Research, vol. 153, pp. 296-309, 2015.

[49] B.-C. Seo, B. Dolan, W. F. Krajewski, S. A. Rutledge, and W. Petersen, "Comparison of single- and dual-polarizationbased rainfall estimates using NEXRAD data for the NASA Iowa flood studies project," Journal of Hydrometeorology, vol. 16, no. 4, pp. 1658-1675, 2015.

[50] T. M. Weckwerth, J. Hanesiak, J. W. Wilson et al., "Nocturnal convection initiation during PECAN 2015," Bulletin of the American Meteorological Society, vol. 100, no. 11, pp. 22232239, 2019.

[51] B. Geerts, D. Parsons, C. L. Ziegler et al., "The 2015 plains elevated convection at night field project," Bulletin of the American Meteorological Society, vol. 98, no. 4, pp. 767-786, 2017.

[52] O. Sungmin and P. E. Kirstetter, "Evaluation of diurnal variation of GPM IMERG derived summer precipitation over the contiguous US using MRMS data," Quarterly Journal of the Royal Meteorological Society, vol. 144, pp. 270-281, 2018.

[53] X. Chen, F. Zhang, and K. Zhao, "Influence of monsoonal wind speed and moisture content on intensity and diurnal variations of the mei-yu season coastal rainfall over south China," Journal of the Atmospheric Sciences, vol. 74, no. 9, pp. 2835-2856, 2017.

[54] J. Sun and F. Zhang, "Impacts of mountain-plains solenoid on diurnal variations of rainfalls along the mei-yu front over the east China plains," Monthly Weather Review, vol. 140, no. 2, pp. 379-397, 2012. 